\title{
Siyawash en el espejo del mito. Un acercamiento desde la academia y el arte
}

\section{Siyawash in the Mirror of Myth. An Approach from Academy and Arts}

\author{
Sujaila Abigail Miranda Moreno \\ Universidad Nacional Autónoma de México \\ Facultad de Filosofía y Letras \\ su.96ways@gmail.com \\ Celia Elena Salazar Cabrera \\ Universidad Nacional Autónoma de México \\ Facultad de Psicología \\ cliaelena7@gmail.com
}

Durante la mañana del 18 de septiembre del 2019 en el Instituto de Investigaciones Filológicas de la UNAM, un letrero afuera del pasillo invita a pasar al Aula Magna para presenciar el inicio de las Jornadas: Siyawash en el espejo del mito. Un acercamiento desde la academia y el arte, organizadas en el marco del proyecto PAPIIT IA 400518 "El recorrido literario del mito de Siyawash desde el Shahnamé de Ferdousí hasta el Sendebar medieval”, con la doctora Shekoufeh Mohammadi Shirmahaleh como encargada del proyecto.

A las 11 de la mañana, da inicio la primera mesa llamada El recorrido literario del mito de Siyawash. Tres investigadoras del Instituto de Investigaciones Filológicas nos hacen conjeturar el profundo acercamiento literario a textos antiguos de diversas culturas y cómo se entretejen sus conocimientos con mitos de la antigüedad y con el Sendebar medieval.

La doctora Shekoufeh Mohammadi, especialista en la literatura persa, nos habla sobre príncipes virtuosos y mujeres engañosas, narrando la vida de un cuento marco - la historia de Siyawash y Sudabé- que ha saltado a través del tiempo, de libro en libro y de cultura en cultura para dar a conocer 
una historia que, al sufrir tantas transformaciones, terminó por desgastarse y perder poco a poco su origen mítico; sin embargo, las palabras de la doctora Mohammadi nos hacen revivir el origen de la historia, y nos plantean el reconocimiento de un príncipe virtuoso, como un dios de la vegetación, y una mujer engañosa, como es la gran diosa poseedora de tres facetas distintas: generadora de vida, destructora de vida y regeneradora de vida.

Por otro lado, la doctora Wendy Phillips, experta en literatura sánscrita, realiza un ejercicio similar y hace varias conexiones con textos de distintas culturas y épocas, y esboza el origen indio de una historia que aparece en el Sendebar. Finalmente, la doctora Carmen Armijo, especialista en la época medieval, concluye la mesa con una ponencia que termina siendo un excelente ejercicio de cuentacuentos, vincula al Sendebar con las Ciento y una noches y las Mil y una noches, teniendo a todos los oyentes encantados. En el tiempo de discusiones y preguntas, queda claro que el recorrido de la leyenda en cuestión es mítico, literario y cultural, y que los cuentos presentes en el Sendebar medieval español, no están disociados del cuento marco que imita la estructura de un mito iranio.

En la segunda mesa: Ritos de ayer y hoy, el doctor José Luis Blesa, de la Universidad Autónoma de Madrid, ofrece una extraordinaria explicación sobre los espacios rituales, incluyendo datos geográficos, ritos y tradiciones dedicados al luto por Siyawash. La maestra Yasaman Dowlatshahi, del Instituto de Investigaciones en Humanidades de Irán, nos habla de los rituales relacionados con Siyawash en el Irán actual y crea un vínculo brillante entre las raíces del mito de Siyawash — que podemos encontrar en el mito babilonio de la diosa Ishtar y el dios Tammuz - y en el mito sumerio de Innana y Dumuzi, con las repercusiones que han tenido en el Irán actual, como la realización del ritual de la "muerte sagrada" del Imam Husáyn.

La última actividad del día está a cargo de Sofía Gama, estudiante de la Facultad de Música de la UNAM, quien ha realizado una composición original en formato de banda sonora para la leyenda de Siyawash en el Shahnamé de Ferdousí. Presenta primero las bases semióticas de su trabajo de composición y después ofrece ejemplos de piezas musicales hechas para cada uno de los personajes de la leyenda. Las características míticas y legendarias de los personajes son la base de su elección de instrumentos y patrones melódicos.

El segundo y último día de las Jornadas, reúne a participantes jóvenes (estudiantes y egresados de licenciatura) de distintas disciplinas como la filosofía, la psicología y la antropología con propuestas novedosas, combina- 
das con un pasado remoto. En la primera mesa, titulada El mito de Siyawash traspasando horizontes, Miguel Ángel Cabrera establece un puente entre Siyawash, Platón y Jenofonte, tomando como centro la palabra griega $\mathrm{Ka}$ lokagathía (virtud), desde donde aborda la tragedia del héroe predilecto del Shahnamé. Después, Celia Salazar Cabrera nos habla sobre el fuego como símbolo de transformación de la conciencia humana vinculado a la leyenda de Siyawash y a sus raíces zoroastrianas. Por último, Judith Jiménez da una ponencia sobre encantamiento y fertilidad, nos habla de los puentes entre las culturas persa, india y mexicana a partir de los mitos concernientes a la Diosa Madre. Esta ponencia sirve además como una introducción al evento artístico que será presentado al final de las jornadas.

La segunda mesa se titula Repercusiones míticas y género. Un eco feminista resuena en las dos jóvenes que presentan una deconstrucción del personaje más controversial de la historia de Siyawash: Sudabé, la madrastra malvada. Ndeni Rojas y Sujaila Miranda hablan de esta mujer con respeto, reconociendo sus poderosos actos en la narración y descubriendo su pasado mítico y divino, para ponerla como ejemplo de una mujer empoderada, de una gran diosa del pasado cuya fortaleza resuena en el presente.

Un ciclo de jornadas tan interesante debía cerrar telón con un acto final de la misma hechura. Termina la mesa, y rápidamente se comienza a preparar el escenario para el espectáculo de música y danzas mexicana e india: Tentación y virtud. Judith Jiménez entra con los músicos y Sofía Rosas inicia el relato de una obra que entreteje la historia de Siyawash con piezas musicales tradicionales mexicanas e indias. Es una festividad colorida, con bailarines que acompañan el espectáculo con una destreza y ánimo invaluables. Todos los asistentes aplaudimos llenos de júbilo, el ánimo que nos invade es como el de quien descubre que se ha terminado una increíble fiesta.

Así como el reflejo de un espejo, el mito y la leyenda de Siyawash fulguraron su simbolismo en la experiencia de los y las asistentes a través del arte, la música, la danza, la cultura, la literatura, la filosofía, la psicología y la antropología, haciendo que nos vinculemos, aunque sea por un instante, con la realidad actual y ancestral de Irán.

\section{Sujaila Abigail Miranda Moreno}

Escritora feminista. Trabaja en la Cátedra Nelson Mandela de derechos humanos de Cultura UnAM. Fue la directora del primer tutorial para casos de violencia 
de género basado en el Protocolo establecido por la UNAM. Ha publicado en el suplemento cultural de la revista Siempre! Ha participado como ponente en el Coloquio de la IX Semana Árabe en México y en el Coloquio de Lingüística forense de la Facultad de Filosofía y Letras. Es becaria del proyecto PAPIT "El recorrido literario del mito de Siyawash desde el Shahnamé de Ferdousí hasta el Sendebar medieval".

\section{Celia Elena Salazar Cabrera}

Tesista de la Facultad de Psicología de la UnAM. Su proyecto de titulación trata sobre "La hermenéutica de lo imaginal en la obra de James Hillman". Ha concluido varios cursos y diplomados sobre mística y religión en el Instituto de Investigaciones Filológicas de la UNAM y en el Instituto Cultural Helénico. Entre sus intereses académicos está el estudio de las lenguas árabe y farsi, y temas como la imaginación simbólica y su vínculo con la mitología y la psicología. 